\title{
Mesoporous High-Surface-Area Copper-Tin Mixed-Oxide Nanorods: Remarkable for Carbon Monoxide Oxidation
}

\author{
Honggen Peng, ${ }^{[a, b]}$ Yang Liu, ${ }^{[a]}$ Yarong Li, ${ }^{[a]}$ Xianhua Zhang, ${ }^{[a]}$ Xianglan Tang, ${ }^{[a]}$ Xianglan $\mathrm{Xu}_{1}{ }^{[a]}$ \\ Xiuzhong Fang, ${ }^{[a]}$ Wenming Liu, ${ }^{[a]}$ Ning Zhang, ${ }^{[a]}$ and Xiang Wang* ${ }^{[a]}$
}

\begin{abstract}
Mesoporous, high-surface-area $\mathrm{Cu}-\mathrm{Sn}$ mixed-oxide nanorods were fabricated for the first time by nanocasting with the use of mesoporous KIT- 6 silica as the hard template. The $\mathrm{Cu}-\mathrm{Sn}$ nanorods are significantly more active than $1 \% \mathrm{Pd} / \mathrm{SnO}_{2}$ for the oxidation of $\mathrm{CO}$ and possesses long-term durability and potent water resistance; they thus have the potential to replace noble metal catalysts for emission-control processes.
\end{abstract}

The morphology of a catalyst is critical for its catalytic performance; therefore, morphology control has become a popular strategy to improve the activity, selectivity, and stability of a catalyst over recent years. ${ }^{[1-9]}$ Metal-oxide catalysts with an elongated rod-shape structure have many advantages, including high surface to volume ratio, preferentially exposed active facets, and good mechanical stability, which are key factors that are used to determine the application potential of the catalysts. ${ }^{[6,10-12]}$ Shen and co-workers ${ }^{[13]}$ reported that $\mathrm{Co}_{3} \mathrm{O}_{4}$ nanorods not only catalyze $\mathrm{CO}$ oxidation at temperature as low as $-77^{\circ} \mathrm{C}$ but also remain very stable in a moisture stream. $\mathrm{MnO}_{2}$ nanorods prepared by the hydrothermal method have also been shown to have much better catalytic performance for toluene combustion than their polycrystalline powder counterpart prepared by the precipitation method. ${ }^{[14]}$ Rod-like $\mathrm{CeO}_{2}$ has been studied as a support for $\mathrm{Au}$ and $\mathrm{NiO}$ to prepare catalysts for the preferential oxidation of $\mathrm{CO}$ in a $\mathrm{H}_{2}$-rich gas ${ }^{[4]}$ and for the selective reduction of $\mathrm{NO}$ with $\mathrm{NH}_{3},{ }^{[15]}$ respectively, and both catalysts show improved reaction performance compared with $\mathrm{CeO}_{2}$ polyhedra and pure $\mathrm{NiO}$. In addition, it was reported that $\mathrm{Mn}$-Ce mixed-oxide nanorods with a high $\mathrm{Mn}$ content also display very high activity and stability for toluene combustion. ${ }^{[16]}$

Our group previously reported that the activity of pure $\mathrm{SnO}_{2}$ nanorods for $\mathrm{CO}$ oxidation is much improved relative to that of other morphologies. ${ }^{[17]}$ Most importantly, their catalytic be-

[a] Dr. H. Peng, Y. Liu, Y. Li, X. Zhang, X. Tang, Dr. X. Xu, Dr. X. Fang,

Prof. Dr. W. Liu, Prof. Dr. N. Zhang, Prof. Dr. X. Wang

Institute of Applied Chemistry, College of Chemistry

Nanchang University

Nanchang, Jiangxi 330031 (China)

E-mail:xwang23@ncu.edu.cn

[b] Dr. H. Peng

School of Chemistry and Chemical Engineering

Shanghai Jiao Tong University

800 Dongchuan Road, Shanghai 200240 (China) $\square$ Supporting Information and the ORCID identification number(s) for the
iD author(s) of this article can be found under http://dx.doi.org/10.1002/

(iD) cctc. 201600221. havior is similar to that of supported noble metal catalysts. Although the specific surface area of this $\mathrm{SnO}_{2}$ nanorod catalyst is as low as $1 \mathrm{~m}^{2} \mathrm{~g}^{-1}$ and even though it does not contain any active oxygen species, it has preferentially exposed [110] facets, which have been shown by other researchers to be the active facets, ${ }_{1}^{[17]}$ but the activity of this $\mathrm{SnO}_{2}$ nanorod catalyst is still lower than that of the comparison sample $1 \% \mathrm{Pd} / \mathrm{SnO}_{2}$. If its activity can be further improved, the $\mathrm{SnO}_{2}$ nanorod catalyst itself could be a good candidate to replace noble metal catalysts. Very recently, mesoporous $\mathrm{SnO}_{2}$ and $\mathrm{Cu}-\mathrm{Sn}$ mixed-oxide nanosheets were successfully prepared by our group, and they showed superior activity and stability for CO oxidation at low temperature owing to the presence of a large amount of mobile oxygen species and their high surface areas. ${ }^{[18]}$ The creation of mesopores in the $\mathrm{SnO}_{2}$ nanorods could increase their surface area, produce mobile oxygen species, and enhance the contact of the reactants with the active sites, which would thus eventually improve the activity of the catalyst so that performance competitive with that of noble metals could be achieved. Nanocasting technology is a versatile method to create non-siliceous nanostructured porous materials. ${ }^{[19]}$ In a casting process, a replica structure can usually be obtained, which is the negative replica. Until now, to the best of our knowledge, there is little research on the use of mesoporous silica as a hard template to prepare mesoporous mixed-oxide nanorods through a nanocasting strategy.

In this communication, a mesoporous silica, KIT-6, with ordered mesopores (Figures S1-S3, Supporting Information) was synthesized and used for the first time as the hard template to prepare $\mathrm{Cu}-\mathrm{Sn}$ metal-oxide nanorods with a $\mathrm{Cu} / \mathrm{Sn}$ molar ratio of $1: 1$ through nanocasting, ${ }^{[19-21]}$ and the resulting catalyst was used for CO oxidation after calcination at different temperatures. The detailed preparation procedures and the reaction condition are described in the Supporting Information.

The SEM and TEM images in Figure 1 demonstrate that the $\mathrm{Cu}-\mathrm{Sn}$ mixed oxide calcined at different temperatures has rodlike morphology. Upon increasing the temperature from 300 to $400^{\circ} \mathrm{C}$, the nanorod becomes elongated and neater. However, a further increase in the calcination temperature to $550^{\circ} \mathrm{C}$ clearly induces the formation of some polycrystalline metaloxide powder, which indicates that part of the rod structure becomes damaged at higher temperatures. As shown in the TEM images in Figure $1 \mathrm{~d}$, on the $\mathrm{Cu}-\mathrm{Sn}$ nanorod calcined at $400^{\circ} \mathrm{C}$, some mesopores are present, and this was further confirmed by the $\mathrm{N}_{2}$ adsorption/desorption results shown in Figure S4. As listed in Table S1, the three samples calcined at different temperatures have similar pore sizes, which are approxi- 

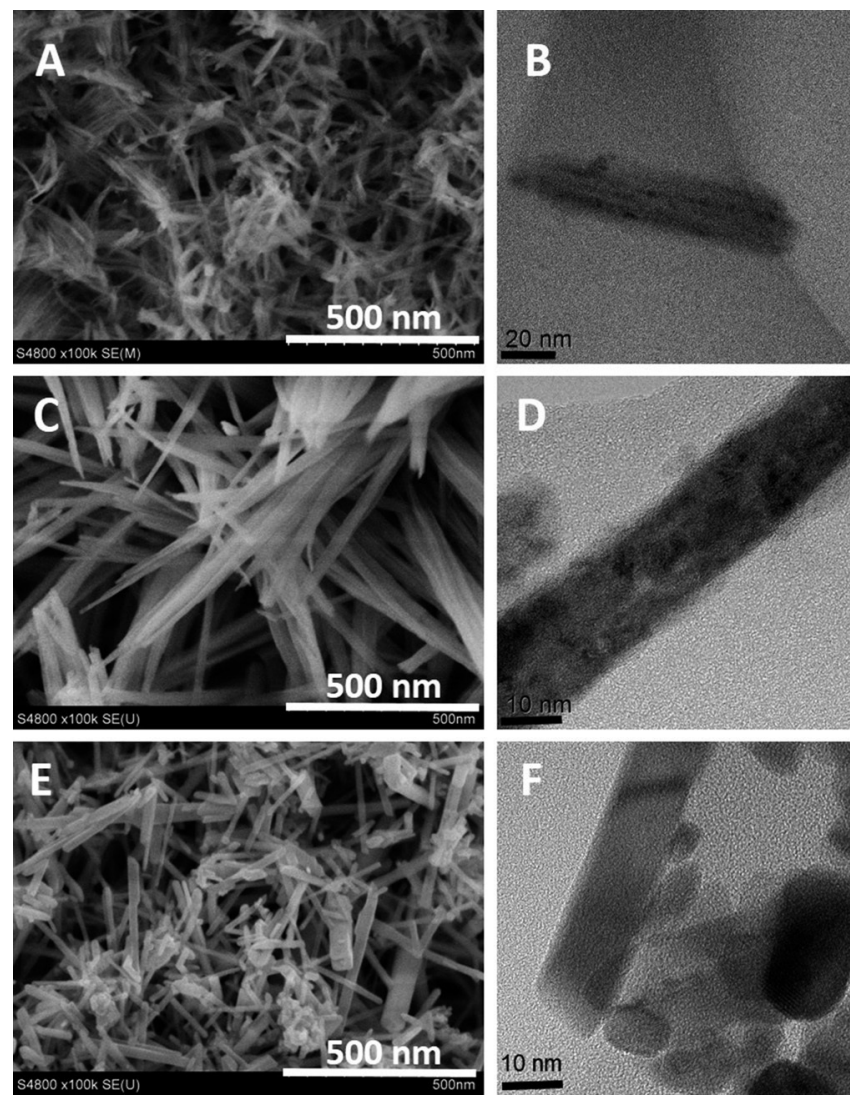

Figure 1. SEM (left) and TEM (right) images of $\mathrm{Cu}-\mathrm{Sn}$ nanorods (molar ratio of $\mathrm{Cu}: \mathrm{Sn}=1: 1$ ) calcined at $\left.\mathrm{a}, \mathrm{b}) 300^{\circ} \mathrm{C}, \mathrm{C}, \mathrm{d}\right) 400^{\circ} \mathrm{C}$, and e, f) $550^{\circ} \mathrm{C}$.

mately $4 \mathrm{~nm}$. Owing to the formation of the mesoporous structure, the surface areas of all three samples are above $110 \mathrm{~m}^{2} \mathrm{~g}^{-1}$, which is much larger than the surface area of the unmodified $\mathrm{SnO}_{2}$ nanorod prepared previously by our group by using the molten salt method. ${ }^{[17]}$ Apparently, the mesoporous structure and high surface area are favorable for the activity of the catalysts.

Usually, by using mesoporous silica as the hard template and the metal oxide as precursor, after removing the template by $\mathrm{NaOH}$ or $\mathrm{HF}$, a replica of the metal oxide is obtained by using the nanocasting method. However, as reported in this communication, a novel mesoporous mixed-oxide nanorod was formed by using the nanocasting method. From the TEM images of the $\mathrm{Cu}-\mathrm{Sn}$ mixed-oxide nanorods, the size of the cross section of the rods is approximately $10 \mathrm{~nm}$, which is very similar to the pore size of KIT-6 (average pore size is $7.8 \mathrm{~nm}$, Figure S2), so the rod-shape structure might be formed by the metal precursor grown along the main cylindrical pores of KIT-6 (Figure S1 c), though KIT-6 is a bicontinuous cubic la3d mesosilica.

To elucidate the phase compositions of the $\mathrm{Cu}-\mathrm{Sn}$ nanorods, the XRD patterns of the samples were compared with the individual $\mathrm{SnO}_{2}$ and $\mathrm{CuO}$ species (Figure S5). All the $\mathrm{Cu}-\mathrm{Sn}$ nanorods clearly show the diffraction features of the tetragonal rutile $\mathrm{SnO}_{2}$ phase, which indicates that a major part of the $\mathrm{Cu}$ cations could have been incorporated into its lattice to form a solid solution structure. ${ }^{[18,22]}$ To confirm this, the $2 \theta$ and $d$ values of the two strongest peaks of the rutile $\mathrm{SnO}_{2}$ phase, peaks (110) and (101), in the $\mathrm{Cu}-\mathrm{Sn}$ nanorod samples were carefully identified and are compared in Table S2. As previously reported, ${ }^{[23,24]} \mathrm{Cu}^{2+}$ with a coordination number $(\mathrm{CN})$ of 6 has a radius of $0.074 \mathrm{~nm}$, whereas that of $\mathrm{Sn}^{4+}$ with the same $\mathrm{CN}$ is $0.069 \mathrm{~nm}$. In comparison with individual $\mathrm{SnO}_{2}$, the two diffraction peaks are shifted to lower angles but the $d$ values increase, which testifies to the expansion of the distance between the crystal facets by incorporation of larger $\mathrm{Cu}^{2+}$ cations into the crystal lattice of $\mathrm{SnO}_{2}$. Indeed, this further proves that a considerable amount of the $\mathrm{Cu}$ cations was introduced into the $\mathrm{SnO}_{2}$ lattice to form a solid solution structure. However, the valence state difference between the two cations is large. As a result, the $\mathrm{Cu}^{2+}$ cations can only be dissolved into the $\mathrm{SnO}_{2}$ lattice with a certain capacity. ${ }^{[25]}$ With a $\mathrm{Cu} / \mathrm{Sn}$ molar ratio of $1: 1$, the amount of $\mathrm{Cu}$ cations clearly exceeds the capacity. Therefore, the $\mathrm{Cu}(\mathrm{OH})_{2}$ phase is observed for the CuSn-rod-300 sample, and $\mathrm{CuO}$ is observed for the CuSn-rod-400 and CuSnrod-550 samples as the minor phases. Notably, upon increasing the calcination temperature, the mean crystallite size of the $\mathrm{SnO}_{2}$ phase becomes larger, which indicates better crystallization of the formed $\mathrm{Cu}-\mathrm{Sn}$ solid solution.

To further clarify the formation of a solid solution structure between the $\mathrm{Cu}$ and Sn oxides, CuSn-rod-400, the typical catalyst in this study, was thus measured by high angle annular dark field (HAADF) scanning transmission electron microscopy (STEM) mapping, and the image is shown in Figure 2. The mapping zone is labeled in the SEM image in Figure $2 \mathrm{a}$, whereas the elemental distribution of the $\mathrm{Cu}, \mathrm{Sn}$, and $\mathrm{O}$ elements is displayed in Figure $2 \mathrm{~b}-\mathrm{d}$. The three elements are distributed very uniformly in the sample, which confirms that
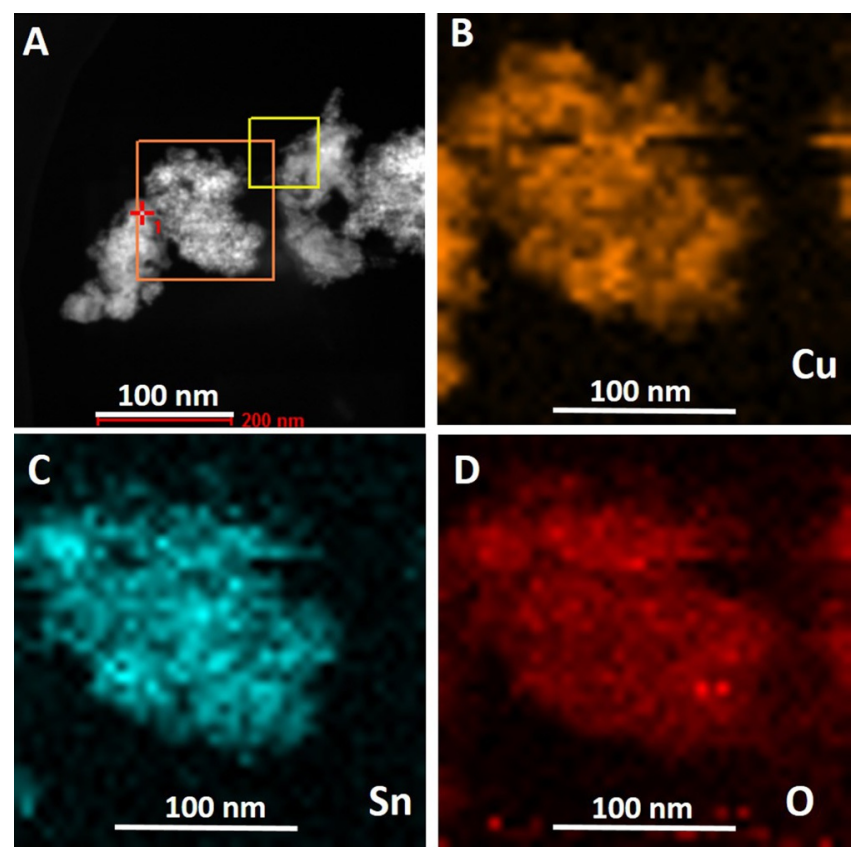

Figure 2. a) HAADF STEM image and b-d) elemental mapping of mesoporous $\mathrm{Cu}-\mathrm{Sn}$ nanorods (molar ratio of $\mathrm{Cu} / \mathrm{Sn}=1: 1$ ) calcined at $400^{\circ} \mathrm{C}$ in air. 


\begin{tabular}{|c|c|c|c|c|c|c|c|c|}
\hline \multirow[t]{2}{*}{ Sample } & \multicolumn{4}{|c|}{$\begin{array}{l}\mathrm{H}_{2} \text { consumption } \\
{\left[\mathrm{mmolg}^{-1}\right]}\end{array}$} & \multirow{2}{*}{$\begin{array}{l}\mathrm{O}_{\text {ads }} / \mathrm{O}_{\text {lat }} \\
\text { (XPS) }\end{array}$} & \multirow[t]{2}{*}{$\begin{array}{l}\text { Reaction rate } \\
{\left[10^{-4} \mathrm{mmol} \mathrm{g}^{-1} \mathrm{~s}^{-1}\right]}\end{array}$} & \multirow[t]{2}{*}{$\begin{array}{l}\text { Reaction rate } \\
{\left[10^{-6} \mathrm{mmol} \mathrm{m}^{-2} \mathrm{~s}^{-1}\right]}\end{array}$} & \multirow[t]{2}{*}{$\begin{array}{l}E_{\mathrm{a}}^{[\mathrm{b}]} \\
{\left[\mathrm{kJ} \mathrm{mol}^{-1}\right]}\end{array}$} \\
\hline & $<240^{\circ} \mathrm{C}$ & $\approx 380^{\circ} \mathrm{C}$ & $>530^{\circ} \mathrm{C}$ & Total & & & & \\
\hline CuSn-rod-300 & 2.5 & 0.7 & 5.7 & 8.9 & 0.6 & 0.3 & 0.114 & 66.5 \\
\hline CuSn-rod-400 & 3.8 & 1.1 & 3.8 & 8.7 & 2.7 & 9.2 & 5.9 & 47.3 \\
\hline CuSn-rod-550 & 3.6 & 0.8 & 3.6 & 8.0 & 1.5 & 4.9 & 4.3 & 50.3 \\
\hline
\end{tabular}

a homogeneous solid solution structure is formed in the $\mathrm{Cu}$ Sn mixed-oxide nanorods.

The redox properties of the samples were studied by temperature-programmed reduction by hydrogen $\left(\mathrm{H}_{2}-\mathrm{TPR}\right)$, and the profiles are shown in Figure $\mathrm{S} 6$; the $\mathrm{H}_{2}$ uptake amount is quantified in Table 1. For all the $\mathrm{Cu}-\mathrm{Sn}$ nanorod samples calcined at different temperatures, three groups of reduction peaks can be distinctly observed below $240^{\circ} \mathrm{C}$, at approximately $380^{\circ} \mathrm{C}$, and above $540^{\circ} \mathrm{C}$. The peak below $240^{\circ} \mathrm{C}$ is assigned to the reduction of $\mathrm{CuO}$ species in the samples into metallic $\mathrm{Cu}^{\left[{ }^{[18]}\right.}$ In contrast, the peak above $530^{\circ} \mathrm{C}$ is assigned to the reduction of $\mathrm{SnO}_{2}$ to metallic $\mathrm{Sn}^{[17]}$ whereas the small peak at approximately $380^{\circ} \mathrm{C}$ is believed to be the reduction of deficient oxygen species induced by the formation of the $\mathrm{Cu}-\mathrm{Sn}$ solid solution structure in the samples. ${ }^{[18]}$ Upon varying the calcination temperature, the reduction behavior of the samples is clearly changed. For low-temperature CO oxidation, the oxygen species reduced at low temperature are believed to be critical for the activity of the catalyst if it follows the Marsvan Krevlen mechanism. ${ }^{[26]}$ Whereas the total amount of $\mathrm{H}_{2}$ consumed by the samples decreases from 8.9 to $8.0 \mathrm{mmolg}^{-1}$, the amounts consumed by the samples at the first two lowtemperature peaks are $3.2,4.9$, and $4.4 \mathrm{mmol} \mathrm{g}^{-1}$ for the CuSnrod-300, CuSn-rod-400, and CuSn-rod-550 samples, respectively. Apparently, CuSn-rod-400, the sample calcined at $400^{\circ} \mathrm{C}$, clearly consumes the largest amount of hydrogen at approximately 240 and $380^{\circ} \mathrm{C}$, which indicates that this sample contains the largest amount of active oxygen species, which are believed to be favorable for $\mathrm{CO}$ oxidation. In comparison, CuSn-rod-300, the sample calcined at $300^{\circ} \mathrm{C}$, possesses the lowest amount of these active oxygen species, possibly as a result of the still presence of a large quantity of $\mathrm{OH}$ groups.

X-ray photoelectron spectroscopy (XPS) was adopted to identify the surface composition of the catalysts, and the spectra are displayed in Figure S7. The binding energies observed in Figure $\mathrm{S} 7 \mathrm{a}, \mathrm{b}$ for $\mathrm{Cu} 2 \mathrm{p}$ and $\mathrm{Sn} 3 \mathrm{~d}$ are typical for $\mathrm{Cu}^{2+}$ and $\mathrm{Sn}^{4+}{ }_{[18]}$ which is in line with the $\mathrm{H}_{2}$-TPR results. The asymmetric $\mathrm{O} 1 \mathrm{~s}$ peaks of the samples shown in Figure $\mathrm{S} 7 \mathrm{c}$ indicate the presence of surface oxygen species with different chemical environments. Therefore, the $01 \mathrm{~s}$ peaks of the samples were deconvoluted, as shown in Figure S7 d-f. Whereas the peak at a binding energy (BE) of approximately $530 \mathrm{eV}$ is assigned to surface lattice oxygen $\left(\mathrm{O}_{\text {lat }}\right){ }^{[27]}$ the peak at a BE of approximately $532 \mathrm{eV}$ is attributed to loosely bonded surface oxygen species $\left(\mathrm{O}_{\mathrm{ads}}\right){ }^{[27]}$ which is believed to be important for the oxidation activity of the catalysts. Therefore, the $\mathrm{O}_{\text {ads }} / \mathrm{O}_{\text {lat }}$ ratios of the samples were quantified and are listed in Table 1. Apparently, the CuSn-rod-400 sample possesses the highest value, which further testifies to that fact that this sample has the largest amount of active oxygen vacancies. Indeed, the XPS results are in agreement with what was detected by the $\mathrm{H}_{2}$-TPR experiments.

The activity of the catalysts was evaluated by $\mathrm{CO}$ oxidation. As shown in Figure $3 a$, CuSn-rod-400, the sample calcined at $400^{\circ} \mathrm{C}$, displays the highest overall activity, on which complete $\mathrm{CO}$ conversion occurred at $130^{\circ} \mathrm{C}$. In comparison with the pure $\mathrm{SnO}_{2}$ nanorod prepared by us, this temperature is $130^{\circ} \mathrm{C}$ lower. ${ }^{[17]}$ Furthermore, its overall activity is even higher than that of $1 \% \mathrm{Pd} / \mathrm{SnO}_{2}$, the comparison catalyst, which achieves complete CO oxidation at $140^{\circ} \mathrm{C}$ (Figure $3 \mathrm{a}$ ). It is clear that with the combination of $\mathrm{Cu}$ and $\mathrm{Sn}$ oxides, $\mathrm{Cu}-\mathrm{Sn}$ nanorods with activity higher than that of supported $\mathrm{Pd}$ can be obtained.

Even though CuSn-rod-300, the sample calcined at $300^{\circ} \mathrm{C}$, has the highest surface area among the three samples, it exhibits the lowest overall activity, which indicates that the surface area is not the determining factor for the activity of the catalysts. To elucidate the inherent reasons accounting for the activity, the differential rates on the samples were collected and are plotted as Arrhenius plots in Figure $3 \mathrm{~b}$. Although CuSn-rod-400 and CuSn-rod-550 evidently have lower surface areas than CuSn-rod-300, they have significantly higher reaction rates under differential conditions. For easy comparison, the differential rate at $100^{\circ} \mathrm{C}$ for each sample is listed in Table 1 together with the overall activation energy. The two samples calcined at higher temperatures not only have higher rates but also have lower activation energies. This strongly indicates that more reactive sites are formed in these two catalysts. As described above, XRD phase analysis indicates that on CuSn-rod-300, the $\mathrm{Cu}(\mathrm{OH})_{2}$ phase is detected instead of the $\mathrm{CuO}$ phase because of the low calcination temperature. It is reasonable to deduce that in this sample, a large amount of $\mathrm{OH}$ groups are still present, which could influence the effective formation of the solid solution structure, as testified by less shifting of the $2 \theta$ and $d$ values. As a result, a smaller amount of active oxygen species is formed, as evidenced by the $\mathrm{H}_{2}$-TPR and XPS results. In contrast, upon increasing the calcination temperature to $400^{\circ} \mathrm{C}$, a larger amount of active oxygen species is produced, but these species will be partly destroyed upon increasing the temperature further to $550^{\circ} \mathrm{C}$ owing to better crystallization. As a consequence, CuSn-rod-400, the 

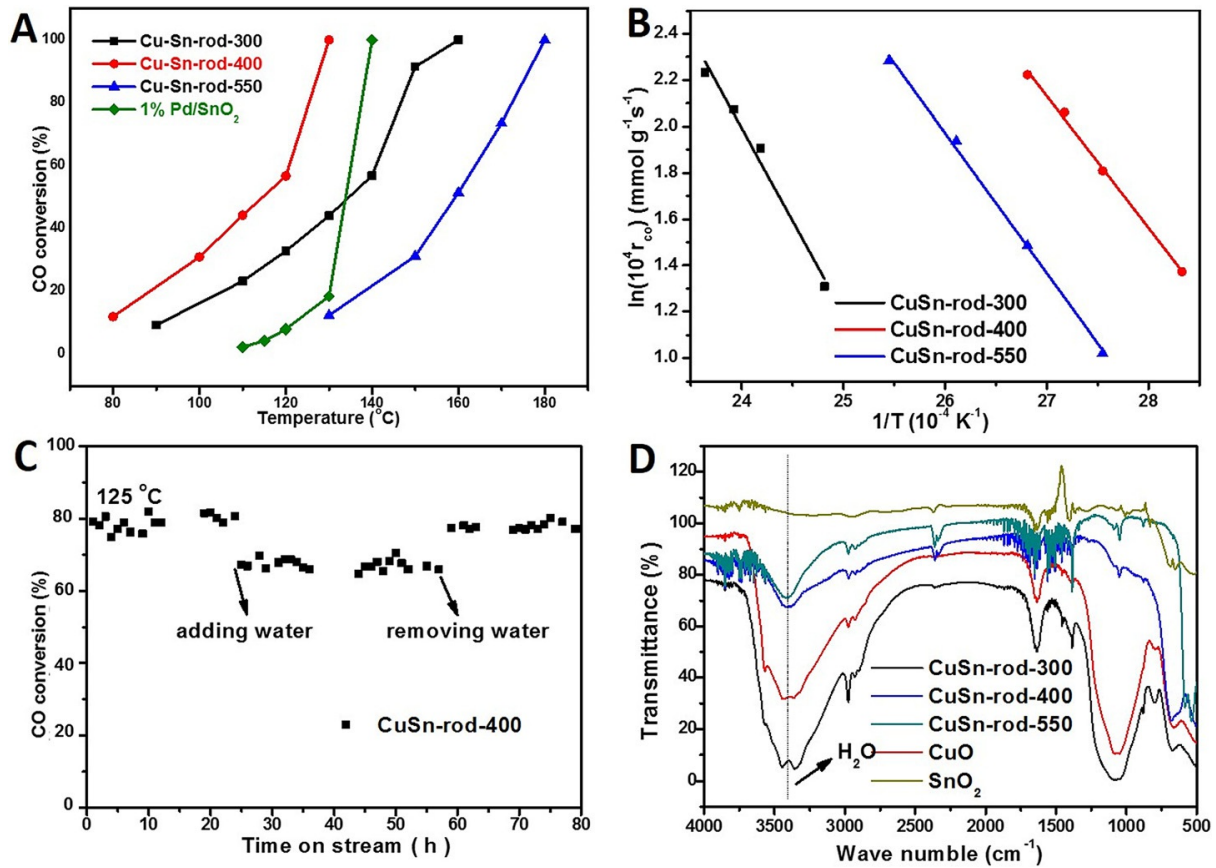

Figure 3. a) CO conversion versus reaction temperatures, b) Arrhenius plots, c) stability test in the absence and presence of water vapor, and d) FTIR spectra of the $\mathrm{Cu}-\mathrm{Sn}$ nanorod samples (molar ratio of $\mathrm{Cu} / \mathrm{Sn}=1: 1$ ) after water adsorption.

sample calcined at $400^{\circ} \mathrm{C}$, displays the highest activity among all the samples.

In real exhaust, $5-10 \%$ water vapor is generally present; therefore, CuSn-rod-400, the optimal catalyst in this study, was subjected to a long-term stability test in the absence and presence of $5 \%$ water vapor. As shown in Figure 3c, after the addition of $5 \%$ water vapor, the CO conversion decreases by approximately $10 \%$, but the conversion can be completely restored after removing the water vapor. Not only does this indicate that CuSn-rod-400 is stable, but it also indicates that CuSn-rod-400 is water resistant. FTIR spectroscopy was thus used to investigate the water adsorption behavior of the samples, and the spectra are shown in Figure $3 \mathrm{~d}$. After saturation in water vapor, followed by purging by He flow to remove any physically adsorbed water, whereas pure $\mathrm{CuO}$ displays an evident water adsorption band at approximately $\tilde{v}=3350 \mathrm{~cm}^{-1}$, the individual $\mathrm{SnO}_{2}$ does not show any adsorption of water. ${ }^{[27]}$ Notably, owing to the initial presence of a large amount of $\mathrm{OH}$ groups in its structure, CuSn-rod-300 displays a big band at $\tilde{v}=3350 \mathrm{~cm}^{-1}$. However, although CuSn-rod-400 and CuSnrod-550 also display water adsorption bands at the same wavenumbers, their integrated areas are much smaller than that of pure $\mathrm{CuO}$, and thus, the combination of $\mathrm{Cu}$ and $\mathrm{Sn}$ oxides can produce catalysts with significantly improved water tolerance.

In summary, mesoporous, high-surface-area $\mathrm{Cu}$-Sn mixedoxide nanorods were successfully fabricated by using mesoporous silica (KIT-6) as the hard template for the first time. Cu cations were incorporated into the crystal lattice of rutile $\mathrm{SnO}_{2}$ to form a solid solution structure, which induced the formation of more active oxygen species. CuSn-rod-400, the nanorod sample calcined at $400^{\circ} \mathrm{C}$, displayed the highest activity for $\mathrm{CO}$ oxidation and was even more active than a comparison Pd catalyst $\left(1 \% \mathrm{Pd} / \mathrm{SnO}_{2}\right)$ under the same conditions. Last but not least, the $\mathrm{Cu}-\mathrm{Sn}$ nanorod catalysts also showed superior stability and water resistance, and thus they are potential replacements for precious metal catalysts for real exhaust cleaning.

\section{Experimental Section}

\section{Synthesis of mesoporous silica KIT- 6 hard template}

The mesoporous silica template with cubic la3d bicontinuous structure (KIT-6) was prepared according to the literature. ${ }^{[1,2]}$ Typically, P123 (9 g, $\mathrm{EO}_{20} \mathrm{PO}_{70} \mathrm{EO}_{20}, \mathrm{Mw}=5800$, Aldrich) was dissolved in distilled deionized water $(326 \mathrm{~g})$ and concentrated $\mathrm{HCl}(17.7 \mathrm{~g}$, $\approx 35-37 \%$ ). Then, butanol (9 $\mathrm{g},>99 \%$ ) was added under constant stirring at $35^{\circ} \mathrm{C}$. After stirring for approximately $1 \mathrm{~h}$, tetraethyl orthosilicate (TEOS; $19.4 \mathrm{~g}, 98 \%$ ) was added to the above solution. The mixture was continuously stirred for another $24 \mathrm{~h}$ at $35^{\circ} \mathrm{C}$ and was subsequently transferred into a $500 \mathrm{~mL}$ Teflon-lined stainlesssteel autoclave and heated at $100^{\circ} \mathrm{C}$ for $24 \mathrm{~h}$ under static conditions. The white precipitate recovered by filtration was thoroughly washed with distilled deionized water, which was followed by drying at $90^{\circ} \mathrm{C}$ overnight. P123 was removed by calcining the asmade materials at $550^{\circ} \mathrm{C}$ for $6 \mathrm{~h}$ in air.

\section{Synthesis of mesoporous $\mathrm{Cu}-\mathrm{Sn}$ nanorods by nanocasting}

Typically, $\mathrm{Cu}\left(\mathrm{NO}_{3}\right)_{2} \cdot 3 \mathrm{H}_{2} \mathrm{O} \quad(3.02 \mathrm{~g}, 12.5 \mathrm{mmol})$ and $\mathrm{SnCl}_{4} \cdot 5 \mathrm{H}_{2} \mathrm{O}$ $(4.38 \mathrm{~g}, 12.5 \mathrm{mmol})$ were dissolved in absolute ethanol $(10 \mathrm{~mL})$ and then KIT- 6 ( $2.5 \mathrm{~g}$, calcined at $200^{\circ} \mathrm{C}$ under vacuum) was added. The mixture was stirred for $1 \mathrm{~h}$ at room temperature. Afterwards, the temperature was increased to $60^{\circ} \mathrm{C}$, and continuous stirring was maintained until the solvent was fully evaporated. The powder was dried at $60^{\circ} \mathrm{C}$ for $12 \mathrm{~h}$ and then calcined at $200^{\circ} \mathrm{C}$ for $4 \mathrm{~h}$ at a heat- 
ing rate of $1{ }^{\circ} \mathrm{Cmin}^{-1}$. The above procedure was repeated except that the solution mixture consisted of $\mathrm{Cu}\left(\mathrm{NO}_{3}\right)_{2} \cdot 3 \mathrm{H}_{2} \mathrm{O}(1 \mathrm{~g})$, $\mathrm{SnCl}_{4} \cdot 5 \mathrm{H}_{2} \mathrm{O}(1.5 \mathrm{~g})$, and absolute ethanol $(5 \mathrm{~mL})$. The obtained sample was then calcined at 300,400 , or $550^{\circ} \mathrm{C}$ for $4 \mathrm{~h}$. After this, the silica template (KIT-6) was removed with an aqueous $2 \mathrm{M} \mathrm{NaOH}$ solution at $65^{\circ} \mathrm{C}$ for $6 \mathrm{~h}$. This etching step was repeated to ensure that the silica template was completely removed. The sample was then dried thoroughly at $90^{\circ} \mathrm{C}$ overnight. The final sample was named CuSn-rod-300, CuSn-rod-400, or CuSn-rod-550, respectively. The elemental compositions of the samples were determined by inductively coupled plasma (ICP), and the results are listed in Table S1. For the samples calcined at 400 and $550{ }^{\circ} \mathrm{C}$, the $\mathrm{Cu} / \mathrm{Sn}$ molar ratios were approximately 1:1, as designed. However, for the sample calcined at $300^{\circ} \mathrm{C}$, part of the $\mathrm{Cu}$ species was lost during the etching process owing to the low calcination temperature, which resulted in a $\mathrm{Cu} / \mathrm{Sn}$ molar ratio of 0.81 .

\section{Catalyst characterization}

The powder X-ray diffraction (XRD) patterns were recorded with a Bruker AXS D8Focus diffractometer operating at $40 \mathrm{kV}$ and $30 \mathrm{~mA}$ with $\mathrm{CuK}_{\alpha}$ irradiation $(\lambda=1.5405 \AA)$. Scans were taken with a $2 \theta$ range from 10 to $90^{\circ}$ for wide angle scan with a step of $5^{\circ} \mathrm{min}^{-1}$ and from 0.5 to $6^{\circ}$ for small angle scan with a step of $1^{\circ} \mathrm{min}^{-1}$. To keep the data comparable, all of the samples were tested continuously under the same conditions. The mean crystallite sizes of the samples were calculated with the Scherrer equation on the basis of the three strongest peaks of $\mathrm{SnO}_{2}$ with $h \mathrm{kl}$ of (110), (101), and (211). The calculated experimental error for $2 \theta$ measurement of the peaks was $\pm 0.01^{\circ}$, which ensured reliable identification of peak shift observed by solid solution formation. The copper and tin contents were determined by inductively coupled plasma atomic emission spectroscopy (ICP-AES) with an IRIS Intrepid II XSP instrument (Thermo Electron Corporation).The scanning electron microscopy (SEM) images were taken with a Hitachi S4800 field emission scanning electron microscope. Transmission electron microscopy (TEM) images were taken with a Tecnai F30 transmission electron microscope. The high angle annular dark field scanning transition electron microscopy (HAADF-STEM) images, elemental phase mapping, and surface scans by energydispersive spectroscopy were also obtained by using a Tecnai F30 transmission electron microscope equipped with an Oxford EDX detector operated at $300 \mathrm{keV}$. Nitrogen adsorption/desorption of the samples was performed at $77 \mathrm{~K}$ with an ASAP2020 instrument. The specific surface areas of the samples were calculated by using the Brunauer-Emmett-Teller (BET) method in the relative pressure $\left(P / P_{0}\right)$ range of 0.05 to 0.25 . The pore-size distributions of the samples were calculated with the Barrett-Joyner-Halenda (BJH) method. The average pore sizes of the samples were obtained from the peak positions of the distribution curves. The total pore volume of each catalyst was accumulated at a relative pressure of $P / P_{0}=0.99$. Hydrogen temperature programmed reduction $\left(H_{2}-T P R\right)$ experiments were performed with a FINESORB 3010C instrument in a $30 \mathrm{~mL} \mathrm{~min}{ }^{-1} 10 \% \mathrm{H}_{2} /$ Ar gas mixture flow. Generally, $50 \mathrm{mg}$ of the catalyst was used for the tests. Prior to the experiments, the catalysts were recalcined in a high purity air flow at $300^{\circ} \mathrm{C}$ for $30 \mathrm{~min}$ to remove any surface impurities. The temperature was then increased from room temperature to $850^{\circ} \mathrm{C}$ at a rate of $10^{\circ} \mathrm{Cmin}^{-1}$. A thermal conductivity detector (TCD) was employed to monitor $\mathrm{H}_{2}$ consumption. For $\mathrm{H}_{2}$ consumption quantification, $\mathrm{CuO}(99.99 \%)$ was used as the calibration standard. X-ray photoelectron spectroscopy (XPS) was performed with a PerkinElmer PHI1600 system by using a single MgK X-ray source operating at
$300 \mathrm{~W}$ and $15 \mathrm{kV}$. The spectra were obtained at ambient temperature with an ultrahigh vacuum. The binding energies were calibrated by using the $\mathrm{C} 1 \mathrm{~s}$ peak of graphite at a binding energy of $284.5 \mathrm{eV}$ as a reference. FTIR spectra were recorded in the 500$4000 \mathrm{~cm}^{-1}$ range with a Nicolet Nexus 670 FTIR spectrometer in absorbance mode at a spectral resolution of $2 \mathrm{~cm}^{-1}$ at room temperature. To measure the water adsorption, the fresh samples were saturated in water vapor prior to the experiments and were subsequently purged by an ultrahigh purity $\mathrm{He}$ flow for $30 \mathrm{~min}$ to remove any physically adsorbed water.

\section{Activity evaluation}

The catalytic performance of the catalysts was evaluated by CO oxidation with a U-shaped quartz tube $(I D=6 \mathrm{~mm})$ reactor with a down flow over $100 \mathrm{mg}$ catalyst. Typically, $0.3-0.4 \mathrm{~mm}$ catalyst particles were used for activity test. A K-type thermocouple was placed on top of the catalyst bed with the thermocouple head point touching the catalyst to monitor the reaction temperature. To measure the light-off behaviors of the catalysts, all data were collected with increasing temperature. The volume composition of the feed gas was $1 \% \mathrm{CO}, 21 \% \mathrm{O}_{2}$, and balanced by high-purity $\mathrm{N}_{2}$, with a flow rate of $40 \mathrm{~mL} \mathrm{~min}^{-1}$, which corresponds to a space velocity of $24000 \mathrm{~mL} \mathrm{~h}^{-1} \mathrm{~g}_{\mathrm{cat}}{ }^{-1}$ ). The reactants and products were analyzed on-line with a GC9310 gas chromatograph equipped with a TDX-01 column and a TCD detector. To obtain steady-state kinetic data, the reaction at each temperature was stabilized at least 30 min before analysis. The flow rate of the $\mathrm{H}_{2}$ carrier gas was $30 \mathrm{~mL} \mathrm{~min}^{-1}$.

\section{Acknowledgements}

This work was supported by the National Natural Science Foundation of China (21263015, 21567016, and 21503106), the Education Department of Jiangxi Province (KJLD14005), and the Natural Science Foundation of Jiangxi Province (20142BAB213013, 20151BAB203024, and 20151BBE50006), which is greatly acknowledged by the authors.

Keywords: copper - mesoporous materials - nanostructures oxidation $\cdot$ tin

[1] W. Huang, Y. Gao, Catal. Sci. Technol. 2014, 4, 3772-3784.

[2] T. Nguyen, C. Dinh, T. Do, Chem. Commun. 2015, 51, 624-635.

[3] Z. Dou, C. Cao, Y. Chen, W. Song, Chem. Commun. 2014, 50, 1488914891.

[4] G. Yi, Z. Xu, G. Guo, K. Tanaka, Y. Yuan, Chem. Phys. Lett. 2009, 479, 128 132.

[5] Y. Li, W. Shen, Chem. Soc. Rev. 2014, 43, 1543-1574.

[6] P. Hu, M. E. Schuster, Z. Huang, F. Xu, S. Jin, Y. Chen, W. Hua, D. S. Su, X. Tang, Chem. Eur. J. 2015, 21, 9619-9623.

[7] A. Pendashteh, S. E. Moosavifard, M. S. Rahmanifar, Y. Wang, M. F. ElKady, R. B. Kaner, M. F. Mousavi, Chem. Mater. 2015, 27, 3919-3926.

[8] F. Wang, H. Dai, J. Deng, G. Bai, K. Ji, Y. Liu, Environ. Sci. Technol. 2012, 46, 4034-4041.

[9] H. Kim, J. Cho, J. Mater. Chem. 2008, 18, $771-775$.

[10] G. Chen, Q. Xu, Y. Yang, C. Li, T. Huang, G. Sun, S. Zhang, D. Ma, X. Li, ACS Appl. Mater. Interfaces 2015, 7, 23538-23544.

[11] S. Zhang, C. Chang, Z. Huang, Y. Ma, W. Gao, J. Li, Y. Qu, ACS Catal. 2015, 5, 6481-6488.

[12] S. Zhuo, J. Zhang, Y. Shi, Y. Huang, B. Zhang, Angew. Chem. Int. Ed. 2015, 54, 5693-5696; Angew. Chem. 2015, 127, 5785-5788.

[13] X. Xie, Y. Li, Z. Liu, M. Haruta, W. Shen, Nature 2009, 458, 746-749. 
[14] F. Shi, F. Wang, H. Dai, J. Dai, J. Deng, Y. Liu, G. Bai, K. Ji, C. T. Au, Appl. Catal. A 2012, 433-434, 206-213.

[15] P. Maitarad, J. Han, D. Zhang, L. Shi, S. Namuangruk, T. Rungrotmongkol, J. Phys. Chem. C 2014, 118, 9612-9620.

[16] Y. Liao, M. Fu, L. Chen, J. Wu, B. Huang, D. Ye, Catal. Today 2013, 216 $220-228$.

[17] X. Wang, L. Xiao, H. Peng, W. Liu, X. Xu, J. Mater. Chem. A 2014, 2, $5616-5619$

[18] Y. Li, H. Peng, X. Xu, Y. Peng, X. Wang, RSC Adv. 2015, 5, 25755-25764.

[19] A. H. Lu, F. Schüth, Adv. Mater. 2006, 18, 1793-1805.

[20] D. Gu, F. Schuth, Chem. Soc. Rev. 2014, 43, 313-344.

[21] B. Tian, X. Liu, H. Yang, S. Xie, C. Yu, B. Tu, D. Zhao, Adv. Mater. 2003, 15, $1370-1374$.

[22] M. J. Fuller, M. E. Warwick, J. Chem. Soc. Chem. Commun. 1973, 210a.
[23] X. Xu, R. Zhang, X. Zeng, X. Han, Y. Li, Y. Liu, X. Wang, ChemCatchem 2013, 5, 2025-2036.

[24] M. Luo, J. Ma, J. Lu, Y. Song, Y. Wang, J. Catal. 2007, 246, 52-59.

[25] X. Xu, F. Liu, X. Han, Y. Wu, W. Liu, R. Zhang, N. Zhang, X. Wang, Catal. Sci. Technol. 2016, DOI:10.1039/c5cy01870f, in press.

[26] Y. Liu, H. Dai, Y. Du, J. Deng, L. Zhang, Z. Zhao, C. T. Au, J. Catal. 2012, $287,149-160$.

[27] X. Xu, X. Sun, H. Han, H. Peng, W. Liu, X. Peng, X. Wang, X. Yang, Appl. Surf. Sci. 2015, 355, 1254-1260.

Received: February 24, 2016

Revised: April 15, 2016

Published online on June 15, 2016 